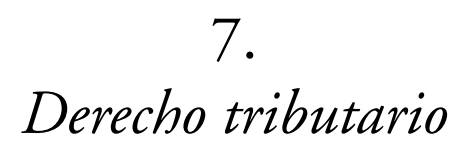



Revista de Derecho

de la Pontificia Universidad Católica de Valparaíso XXIX (Valparaíso, Chile, $2^{\text {do }}$ Semestre de 2007)

[pp. $351-378]$

\title{
EL ERROR, LA SIMULACIÓN, EL FRAUDE A LA LEY Y EL ABUSO DE UN DERECHO EN EL DERECHO TRIBUTARIO CHILENO
}

[Mistake, Simulation, Fraud to the Law and the Abuse of a Right in the Chilean Tax Law]

\author{
Rafael Martínez Cohen* \\ Pontificia Universidad Católica de Valparaíso
}

\begin{abstract}
RESUMEN
La obligación tributaria emana de la ley, y sólo puede nacer de un hecho jurídico, el hecho imponible, no pudiendo generarse a partir del error o de la simulación lícita, por faltar la voluntad en el acto o contrato. La evasión siempre será ilícita, y dará origen al cobro tributario. La elusión será antijurídica si se efectúa con el único fin de defraudar al fisco, en fraude a la ley o en abuso de un derecho, mas sólo podrá solicitarse indemnización de perjuicios por parte del Estado en el juicio criminal por delitos tributarios, pues no se permitiría la liquidación de impuestos en dichos casos.
\end{abstract}

Palabras Clave: Error - Simulación - Fraude a la ley - Abuso.

\begin{abstract}
Tax obligation arises from the law, and can only come from a legal fact, the taxable fact, and cannot arise from a mistake or from legal simulation for the lack of will from the act or contract. Evasion will always be illicit and will give rise to tax collection. Evasion shall be illegal if perpetrated with the only aim to defraud the Internal Revenue System, if defrauding law or abusing a right, but the State will only be able to require compensation for damages in the criminal trial over tax crimes, since the settlement of taxes will not be allowed in those cases.
\end{abstract}

KeYwords: Mistake - Simulation - Fraud against the law - Abuse.

* Profesor de Derecho Tributario en la Facultad de Derecho de la Pontificia Universidad Católica de Valparaíso. Dirección Postal: Avenida Brasil 2950, Valparaíso, Chile. Correo Electrónico: rmartinezc@vtr.net 


\section{INTRODUCCIÓN}

Como es ampliamente sabido, la obligación tributaria es de aquellas que tienen su fuente en la ley. Sobre el particular, no debemos perder de vista el artículo 1437 del Código Civil, que establece a la ley como fuente de las obligaciones.

Así las cosas, para que nazca la obligación tributaria, materialmente el sujeto pasivo de la obligación debe realizar expresamente el hecho descrito en abstracto en la ley, de allí su carácter excepcional, lo que proscribe su interpretación por analogía, tal como lo ha aceptado la mayoría de los autores y de la jurisprudencia.

Ello no es óbice para que en ciertos impuestos se grave la celebración de un acto o contrato como hecho imponible, por ejemplo, en la Ley del Impuesto de Timbres y Estampillas. En dichos casos, la obligación tributaria y la obligación civil nacen coetáneamente, aun cuando con diversos efectos.

En definitiva, lo que interesa al Derecho Tributario en dichos casos no es el contrato en sí mismo, que sólo genera obligaciones entre las partes, sino en cuanto hecho gravado de un impuesto, es decir, un hecho jurídico de interés tributario, aun cuando materialmente se manifieste en un acto jurídico.

Hay que recalcar en este punto que, a diferencia del Derecho Civil, en que las partes pueden acordar las cláusulas que quieran, conforme al artículo 1545 del Código Civil, introduciendo ficciones aceptadas por ambos contratantes, aunque no se correspondan con la realidad, en la medida que no perjudiquen los derechos de terceros, en materia tributaria dichas ficciones no pueden tener efecto alguno por el principio de la realidad que venimos enunciando.

Esta distinción es la diferencia determinante entre el Derecho Privado y el Derecho Tributario, a la hora de interpretar este último, pues, si entendemos que en el Derecho Privado no está en juego el interés público (o por lo menos no es tan relevante) los contratos afectarán por regla general sólo a las partes que en él intervienen, en la medida que no dañen derechos de terceros.

En dicha virtud, los contratantes pueden aceptar en principio ciertos convencionalismos que constituyen ficciones, que configuran hechos no existentes en la vida diaria, pero que éstos deciden dar por reales, que a nadie perjudican, pero que dan certeza a los contratantes frente a eventuales conflictos futuros respecto de su contraparte.

Es más, en el Derecho Privado incluso se puede señalar que se tolera el uso de ficciones, y se aceptan sin reparos, con fines netamente privados, figuras que derechamente tienden a ocultar la realidad, como por ejemplo en el contrato de asociación o cuentas en participación ${ }^{1}$.

\footnotetext{
${ }^{1}$ Sin embargo, aún en el Derecho Civil el tema no es tan pacífico, pues existen
} 
En cambio, y aún con mayor razón, en el Derecho Tributario se trata de investigar, no las ficciones que las partes han acordado, pues como tales no se corresponden con la realidad ${ }^{2}$ precisamente por tratarse de una obligación legal que nace, no como consecuencia de un acuerdo de voluntades, sino que de la realización de un hecho jurídico que debe ser probado.

Así lo ha dicho por lo demás la Corte Suprema: "El principio de la autonomia de la voluntad y de la libre contratación crea una ficción que consiste en asignarle al contrato, legalmente celebrado, el carácter de ley, pero para los contratantes, esto es, se establece que un contrato tiene para ellos la misma fuerza que una ley, pero dicha fuerza de ley no obliga al Estado ni a los tribunales en lo tocante a su contenido, quienes deben, enfrentados a un caso concreto, precisar su alcance. En el campo del derecho tributario carece por completo del sentido que se le ha querido asignar y que se le ha dado por el fallo recurrido, ya que la ley ha entregado normas claras y precisas para la determinación de los tributos que gravan, como en el presente caso, determinadas operaciones, precisamente para sacar del ámbito privado la facultad de fijar un elemento como el precio, que es el que determina la entidad del mismo, puesto que ello conduciría a que los particulares establecieran por si mismos, si deben tributar y en qué cantidad, lo que como ya se dijo, no es aceptable"s.

Que los hechos jurídicos deben ser probados sin las limitantes probatorias propias de los contratos, lo ha resuelto expresamente la jurispruden$\mathrm{cia}^{4}$, y lo expone claramente López Santa María5: "Cuando un contrato es materia de litigio, las partes, evidentemente, deben aportar la prueba de su

autores como López Santa María, Jorge, Sistemas de Interpretación de los Contratos (Valparaíso, Ediciones Universitarias de Valparaíso, 1971), pp. 103 -105, que van más allá, señalando que siempre es la voluntad real la que debe prevalecer a la hora de la interpretación de los contratos, independientemente de las ficciones que hubieren acordado las partes; dice al respecto: "[...] nos parece que debería eliminarse de la interpretación de los contratos toda referencia a voluntades tácitas, probables o virtuales de los contratantes. Estas nociones no tienen ningún sentido. O hay elementos de convicción suficientemente fuertes y entonces la voluntad es real, o no los hay y entonces la voluntad es impenetrable, inútil, por ende, a la interpretación./ [...] el derecho y la interpretación deben integrarse a la realidad a la vida social, donde no hay lugar para consideraciones puramente abstractas y ficticias".

${ }^{2}$ Sobre el concepto de ficciones y su relación con las presunciones, PASCAL GARCía- Huidobro, Enrique De las presunciones (Memoria de Prueba, Universidad de Chile, s.d., s.l.) pp. 56-58.

${ }^{3}$ Excma. Corte Suprema, sentencia del 24 de enero de 2002, rol № 4.426-00.

${ }^{4}$ Acerca de la abundante jurisprudencia sobre la materia: ver Rioseco ENRÍQUEZ, Emilio, La prueba Ante la Jurisprudencia (2a Edición, Santiago, Editorial Jurídica de Chile, 1995), II, pp. 34-40; y Somarriva Undurraga, Manuel, Las obligaciones y los contratos ante la jurisprudencia (Santiago, Editorial Nascimento, 1939), pp. 119122.

${ }^{5}$ López Santa María, Jorge, ob. cit., pp. 65-67, refiriéndose al derecho civil y al Código francés, cuyas disposiciones son idénticas a las del Código Civil chileno. 
existencia. Las limitaciones de los artículos 1341 y siguientes del Código Civil, relativas a la prueba testimonial y a la prueba de presunciones, son entonces aplicables pues tales disposiciones se refieren, precisamente, a la prueba de la existencia de los actos jurídicos./ Esas disposiciones no se aplican, en cambio, a la prueba de los hechos. Ahora bien, las circunstancias de la especie, los elementos extrínsecos al contrato, son siempre hechos materiales que también es menester probar, pero sin que sea necesario tomar en cuenta las limitaciones establecidas para la prueba de los actos jurídicos. Si fuere de otro modo, si se exigiera un principio de prueba por escrito para la prueba de cualquiera circunstancia, la interpretación extrínseca casi no podría tener lugar y por tanto el intérprete lograría muy difícilmente descubrir la voluntad interna de los contratantes./ Si está prohibido por el artículo 1341, probar, más allá de los escritos o contra ellos, "no puede serlo en materia de interpretación pues, cuando se trata de interpretar, se busca solamente despejar cuál ha sido el verdadero alcance de un compromiso y de un contrato, y en tal caso todos los elementos de convicción son utilizables, aun los testimonios, aun las presunciones; es lo que sostiene muy justamente la Corte de Casación en un fallo del 31 de mayo de 1948".

La anterior aseveración no solo se plantea en nuestro medio nacional, sino que ha sido objeto de acabados estudios, sobre todo en relación con la doctrina de la interpretación del Derecho Tributario conforme a la realidad económica, que en definitiva propone interpretar las normas tributarias (algunos autores sostienen que incluso los hechos), no en base a entelequias o abstracciones jurídicas, sino a la realidad, tal cual ha ocurrido en la vida material ${ }^{6}$.

Así las cosas, una de las diferencias fundamentales entre el Derecho Civil y el Derecho Tributario radica precisamente en la amplitud que debe tener la interpretación de sus normas, ya que en este último se debe investigar más que la voluntad aparente de las partes (principio propio del Derecho Civil) ${ }^{7}$, la voluntad real de los contratantes, tal cual sucedieron los eventos en la vida real.

En virtud de lo expuesto, tenemos que, tanto el contribuyente como

${ }^{6}$ Sobre la doctrina de la interpretación según la realidad económica, véase SILVA Pizarro, Manuel, en La Semana Jurídica No 32 pp. 5-6; Brzovic González, Franco, La interpretación de las leyes tributarias, en VV. AA., Interpretación, integración y razonamientos jurídicos (Santiago, Editorial Jurídica de Chile, 1992), pp. 423-427.

${ }^{7}$ Postura que más bien es un lugar común, pues, como hemos expuesto en la nota No 5 , y según veremos más adelante, la opinión prevaleciente en la doctrina pasa a ser precisamente la contraria, al exigirse la investigación de la voluntad real de los contratantes en todo caso. 
el fiscalizador, en su caso, deberán probar la existencia o inexistencia de los hechos gravados que establece la ley, transformándose normalmente la determinación de la obligación tributaria en una cuestión de hecho, a probar por las partes.

Establecido lo anterior, tenemos que concluir que en materia tributaria se debe probar la existencia de hechos jurídicos, y ello deberá hacerse mediante los medios de prueba que autoriza la ley.

La prueba del hecho imponible puede ser realizada por el contribuyente, si es él quien determina el impuesto en su declaración, o por el Servicio, efectuando una liquidación posterior.

Sobre este punto en particular, debemos señalar que los medios de prueba en materia tributaria no difieren de aquellos establecidos en las leyes civiles. En lo que sí se diferencian es en cuanto a la forma en que se pueden obtener por parte del ente fiscalizador, si es éste quien desea probar la existencia de una obligación tributaria mayor a la declarada por el contribuyente.

Así por ejemplo, el valor probatorio de los documentos obtenidos en una fiscalización es idéntico al de los acompañados en un juicio civil. Sin embargo, lo que varía es la forma en que el Servicio puede obtener dichos medios de prueba.

Similar cosa sucede con un particular medio de prueba, cual es la presunción de veracidad que emana de los actos certificados por ministros de fe, que en materia tributaria cobra enorme relevancia, en virtud de que el artículo 86 del Código Tributario les confiere tal carácter a los funcionarios del Servicio que el Director determine.

A continuación, expondremos aquellas circunstancias en que la realidad de los hechos, o la voluntad de las partes, no se condicen con los actos o contratos celebrados por los contribuyentes, a fin de establecer sus efectos en materia tributaria.

\section{SOBRE EL ERROR EN MATERIA TRIBUTARIA}

El primer problema se genera cuando en determinados instrumentos se consignan declaraciones del contribuyente que se vuelven en su contra, por ejemplo, en la contabilidad, en la documentación tributaria, o en las escrituras, tanto públicas como privadas, en que en ellos no consta una voluntad real de parte de quien los suscribe o completa, sino que, en virtud de un error de aquél, o de una simulación lícita de los contratantes, en ellos se estampa un hecho que no se aviene con la realidad, tal cual sucedió en el mundo material.

Sobre este punto, debemos señalar en primer lugar que sólo la confesión 
judicial produce plena prueba en contra de quien la emite, conforme al artículo 1713 del Código Civil. Por tanto, la confesión extrajudicial, que emana de los libros o papeles del contribuyente, constituye sólo la base de una presunción judicial, conforme al artículo 398 del Código de Procedimiento Civil, la que siempre puede ser destruida, de ser ello necesario, por prueba en contrario.

Nuestra tesis es que, ni el error del contribuyente, ni la simulación lícita, en caso alguno pueden dar nacimiento a la obligación tributaria, como frecuentemente lo pretende el Servicio de Impuestos Internos. De hecho, un importante porcentaje de liquidaciones se cursa en la práctica, más que producto de evasiones detectadas, basándose en errores manifiestos en que ha incurrido el contribuyente.

En cuanto al error de hecho (pues no de Derecho, que puede dar lugar a otro tipo de controversia), si éste en materia civil vicia el consentimiento, y por tanto anula la obligación, en materia tributaria sucederá algo similar, al impedir que nazca la obligación tributaria, pues se declaró por escrito algo que no se correspondió con la realidad de los hechos acaecidos.

Aún más, la obligación tributaria carecería de voluntad o de causa real (por tanto sería inexistente, o al menos nula absolutamente) si se basara en un mero error del contribuyente, habiendo un enriquecimiento sin causa de parte del Fisco.

Sobre este punto, hay que señalar que en el tema del error en materia tributaria nunca puede aplicarse la doctrina de los actos propios, pues ésta exige como uno de sus elementos determinantes el hecho de que el acto propio lesione intereses o expectativas de terceros, lo que no se da en la especie, pues sería impresentable sostener que el Servicio tenga interés o expectativas en determinar impuestos basado en un mero error del contribuyente.

Este razonamiento tan básico es reconocido expresamente en nuestra legislación tributaria, que lo establece como un principio transversal que cruza todo el Derecho Tributario. Así, por ejemplo, si el error se comete en la contabilidad, siempre se podrá corregir mediante otro asiento contable, en cualquier tiempo, cuando se notare la falta (artículo 32 del Código de Comercio).

Por otro lado, si el error se comete en las declaraciones de impuestos, se podrán corregir éstas, e incluso solicitar la devolución de los impuestos indebidamente pagados dentro de tres años de ocurrido el error (artículo 126 del Código Tributario).

Es más, dicho Código incluso faculta al contribuyente para rectificar errores propios en la contestación de la citación, e incluso en el reclamo de liquidaciones (artículos 63 inciso $2^{\circ}$ y 127 del Código Tributario). 
En virtud de lo expuesto, si estimamos como un principio general del Derecho Tributario, que el error nunca puede generar una obligación tributaria, y siempre es corregible (por cuanto no se corresponde con la realidad) con mayor razón el contribuyente podrá alegar éste, y por ende probar su existencia, descargándose de la obligación que se le atribuye en una liquidación o giro de impuestos.

\section{SOBRE LA SIMULACIÓN EN MATERIA TRIBUTARIA}

\section{Conceptos previos.}

Al utilizar la palabra "simulación" nos referimos a "El concierto o inteligencia de dos o más personas, autores de una convención o contrato, para engañar a terceros" y por simulación ilícita./ "Aquella que se celebra con la intención positiva de perjudicar a terceros" 8 .

Trasladado el tema a lo tributario, sería contrato simulado aquél en que dos o más personas se conciertan para engañar y perjudicar al fisco.

Consideramos que la simulación ilícita corresponde a lo que comúnmente se denomina evasión. Veamos qué se ha dicho de ella y del concepto de elusión, diferenciando ambos además del de planificación tributaria9: "En la planificación el contribuyente opta por una de las alternativas dispuestas por el legislador en forma expresa o implícita para que los particulares organicen sus negocios./ Entendemos que en la elusión existe un escalón o un grado superior a la simple planificación tributaria, puesto que en la primera son muchas las ocasiones en que el contribuyente utiliza formas jurídicas infrecuentes o atípicas o bien "se aprovecha" de lagunas, vacíos, errores o contradicciones del legislador./ Diferencias entre elusión y evasión: La diferencia está en que en la elusión el contribuyente impide el nacimiento de la obligación tributaria situándose en una zona donde no llega la ley tributaria mediante un medio lícito, aun cuando sea infrecuente./ En cambio, en la evasión la obligación tributaria nació y el contribuyente mediante una maniobra dolosa impide que la Administración Tributaria la conozca o permite que la conozca, pero no por su verdadero monto./ [...] en la elusión no se realiza el hecho imponible; y en la evasión, sí se realiza el hecho imponible, y por lo tanto nace la obligación tributaria, pero dicha realización o su verdadera dimensión económica, se oculta a la Administración./ En materia tributaria nos encontramos

${ }^{8}$ Diez Duarte, Raúl La simulación de contrato en el Código Civil chileno (Santiago, Fallos del Mes, 1982), p. 105.

${ }^{9}$ Ugalde Prieto, Rodrigo - García Escobar Jaime, Elusión, planificación y evasión tributaria (Santiago, LexisNexis, 2006), en diversos extractos que se reproducen a continuación. 
fundamentalmente con la simulación ilícita ya que su objetivo es afectar el patrimonio del Fisco, ya sea disminuyendo o derechamente, haciendo desaparecer la carga tributaria”.

En nuestro concepto, no habrá simulación ilícita en materia tributaria si las partes han simulado un contrato, no para defraudar al fisco, sino que para otros fines, por ejemplo, hereditarios.

En virtud de lo expuesto, es evidente que el fenómeno de la simulación ilícita se corresponde claramente con el de la evasión, no así el de planificación tributaria y el de la elusión.

\section{Sobre la simulación lícita.}

Entendemos que existe simulación lícita en materia tributaria en aquel contrato o convención en el que, con finalidades no tributarias, las partes han mentido u ocultado el verdadero acto o contrato acordado. Por ejemplo, la compraventa entre el padre y el hijo no sujeto a patria potestad celebrada no con la intención de evadir el impuesto a las herencias, sino con el afán de perjudicar a otros herederos; o la venta simulada a terceras personas a fin de burlar los derechos de los acreedores, pero sin la intención de producir ahorro tributario alguno; o bien el abultamiento del precio de compra de un bien raíz para obtener un mayor monto por créditos hipotecarios de parte del Banco; y, en fin, el ejemplo más clásico de simulación o error, según se le mire, que se da cuando las partes dicen pagar al contado por la compra de un bien raíz cuando en realidad lo están comprando a crédito, o lo han pagado con anterioridad.

En todos los casos antes mencionados la realidad siempre debe prevalecer sobre la voluntad aparentemente manifestada, pues no se está mintiendo para causar perjuicio al fisco, para pagar menos tributos, en cuyo caso habría evasión, sino que con otras finalidades extra tributarias. Ello es inconcuso a la luz de la teoría de la interpretación de la ley tributaria conforme a la realidad económica, que ya hemos expuesto.

En el orden procesal, se ha señalado en algunos fallos y doctrina que la simulación para que surta efecto en materia tributaria debe ser judicialmente declarada.

Creemos que dicha aseveración no es correcta, pues es evidente que en un juicio civil entre partes, para que se declare la nulidad de un contrato en virtud de una simulación será menester que exista una declaración previa de un tribunal, pues allí se está solicitando la nulidad, y por tanto la privación de sus efectos.

En el orden tributario el razonamiento es totalmente diverso, pues el valor de un acto o contrato estará dado, no por su validez o nulidad civil, generada por la simulación, sino por su fidedignidad o concordancia con 
la realidad, conforme al artículo 21 del Código Tributario.

Sobre este punto, tenemos que señalar que si un tribunal ordinario declara la nulidad del acto o contrato por simulación, tanto mejor, pero si no existe dicha declaración previa, de todas formas el Servicio podría prescindir del acto simulado por ser no fidedigno, es decir, por no corresponderse con la realidad.

Ahora bien, si el Servicio puede prescindir de los antecedentes del contribuyente por ser no fidedignos, por cuanto no se ajustan a la realidad material, la lógica indica que esos mismos antecedentes, libros o documentos, que no dicen la verdad, y por tanto no se ajustan a la realidad, y en los que nunca existió una simulación ilícita desde el punto de vista tributario, pueden ser dejados de lado por el contribuyente, a fin que finalmente se devele la verdad tal cual ocurrió en la vida real.

Hay que precisar sí que éste deberá acreditar en forma fehaciente la existencia del error o de la simulación lícita, pues en dichos libros o antecedentes opera una presunción en su contra, como lo expondremos más adelante.

En virtud de lo expuesto, a nuestro juicio, siempre se le debe permitir al contribuyente la prueba de haber simulado un contrato con fines no tributarios, o el haber cometido un error.

En general, aquella no ha sido la doctrina tradicional del Servicio de Impuestos Internos, el que sólo a partir de la circular No 68 de 1997, y actualmente en la circular No 8 de $2000^{10}$, ha reconocido expresamente la posibilidad de probar que las declaraciones efectuadas en una escritura pública no fueron reales, pero sólo en el caso de justificación de inversiones, señalando en lo pertinente: "Procede examinar la posibilidad de que un contribuyente sometido a un proceso de justificación de inversiones, intente demostrar que las declaraciones formuladas en un instrumento público suscrito por él, no corresponden a la realidad./ Sobre el particular, se debe tener presente que de acuerdo al artículo $1700^{\circ}$ del Código Civil, el instrumento público hace plena fe contra los declarantes, en cuanto a la verdad de las declaraciones que en él hayan formulado los interesados. I El que un medio de prueba haga plena fe, significa que por si solo basta para establecer la existencia del hecho, pero no impide que se contradiga $y$ pruebe lo contrario por otros medios [...]. En estas condiciones, el contribuyente puede intentar contradecir lo dicho por él en un instrumento público si incurrió en un error, omisión, o imprecisión, pero sólo podrá tener éxito si logra rendir otra plena prueba en contrario, que permi-

${ }^{10}$ Ver en www.sii.cl, “Sección de circulares”, años 1997 y 2000. 
ta en definitiva al revisor o juez apreciar soberanamente la prueba y elegir la que crea más conforme a la verdad (Articulo 428 Código de Procedimiento Civil”.

Sobre este punto, debemos acotar que no se divisa motivo alguno de por qué se aplica el razonamiento antes descrito sólo al tema de justificación de inversiones, y no en materia general en Derecho Tributario.

De acuerdo con el razonamiento señalado, siempre podría el contribuyente poder impugnar lo dicho por él en un instrumento público.

El razonamiento anterior también debería aplicarse a la factibilidad de la prueba del error o de la simulación lícita contenida en los instrumentos privados, pues respecto de las declaraciones en ellos contenidos no opera la presunción en contra de los declarantes establecida en el artículo 1700 del Código Civil.

Instrumentos privados son también dos tipos de documentos, que la propia circular se encarga de tipificar: "Los documentos oficiales, que podemos definir como aquellos que para satisfacer necesidades públicas se expiden o firman por un funcionario público en su carácter de tal (no se "autorizan"), además de estar amparados por la presunción de verdad de toda declaración, se encuentran revestidos por la presunción de legitimidad de los actos del Estado, razón por la cual, atento a su naturaleza y circunstancias especificas, pueden bastarse a si mismo para probar el hecho o acto de que dan cuenta.I En una acepción restringida, son instrumentos privados los otorgados por los particulares sin intervención de funcionario público en su calidad de tal, que testimonian actos o contratos, es decir, dan cuenta de la creación, existencia, modificación o extinción de una obligación./ Por regla general se exige que el instrumento privado esté firmado por los otorgantes, porque la firma es el signo que demuestra que se aprueba o hace propio lo escrito./ No obstante lo anterior, hay documentos que si bien no son instrumentos privados en la acepción técnica y restrictiva de estas palabras, por no estar firmados y/o no testimoniar un acto jurídico, constituyen formalidades testificativas, que en caso de no estar discutida su autenticidad pueden establecer la prueba de un hecho relevante. Por ejemplo, una cartola de cuenta corriente $u$ otros documentos bancarios, a pesar de no estar firmados, pueden reflejar el traspaso o mantención de los fondos que luego derivaron en la inversión. Asimismo, el Servicio ha reconocido eficacia a las facturas de compra o venta de dólares para justificar en materia de inversiones, transacciones de la moneda extranjera efectuadas en el mercado informal, a pesar de no ser instrumentos privados en el sentido estricto de la definición".

Dentro de los documentos privados u "oficiales" por excelencia tenemos que mencionar los libros de contabilidad, y particularmente las facturas, guías de despacho, boletas, etc., por lo que, en virtud del razonamiento 
que venimos exponiendo, también podrían ser impugnados por el propio contribuyente que los llenó.

Un clásico ejemplo de anotaciones que se vuelven en contra del contribuyente son las efectuadas en la contabilidad de aquél, basándose el Servicio para su cobro en el artículo 38 del Código de Comercio, norma no siempre bien interpretada, por lo que se expone a continuación.

De acuerdo al artículo 38 del Código de Comercio: "Los libros hacen fe contra el comerciante que los lleva y no se admitirá prueba que tienda a destruir lo que resultare de sus asientos". Esta norma bien entendida es aplicable sólo a los comerciantes, y en la medida que se hagan valer los libros en contra de éstos en causas de comercio que agiten entre sí, lo que se deduce claramente del contexto en que se ubica dicha norma. Según señala Composto, "En materia comercial los libros sólo tienen un valor probatorio en juicio entre comerciantes, según se establece en los artículos 33, 34 y 35 del Código de Comercio" ${ }^{\text {1. }}$.

En todo caso, y aun cuando se aceptara la tesis de que los libros no pueden ser desmentidos por quien los lleva, siempre estará excluido de la aplicación de dicha norma aquel contribuyente que lleve contabilidad completa o simplificada que no sea comerciante.

En ese mismo orden de ideas, hay que aplicar exactamente el mismo razonamiento respecto de toda documentación que sirva de base a la contabilidad del comerciante, pues ésta carece de valor sin la correspondiente documentación respaldatoria ${ }^{12}$.

Por otro lado, ya hemos señalado que los asientos contables pueden corregirse en cualquier tiempo mediante otro asiento en caso de error, conforme al artículo 32 del Código de Comercio.

Sin perjuicio de lo expuesto, también debe tenerse presente el artículo 1704 del Código Civil que señala: "Los asientos, registros y papeles domésticos únicamente hacen fe contra el que los ha escrito o firmado, pero sólo en aquello que aparezca con toda claridad, y con tal que el que quiera aprovecharse de ellos no los rechace en la parte que le fuere desfavorable".

Ahora bien, ¿qué se entiende por asientos, registros y papeles domésticos, para que hagan fe en contra del contribuyente?

La ley no ha definido el término "doméstico", por lo que debemos

${ }^{11}$ Composto Canales Arnolfo, Manual de contabilidad para abogados (Santiago, Editorial Jurídica de Chile, 1996), p. 119.

${ }^{12}$ Composto, cit (n. 11), p. 121: "En primer lugar se exige respaldo documentario, a diferencia de la legislación mercantil (artículo $21 \mathrm{C}$. Tributario). El asiento registrado sin el documento que acredite la veracidad de la operación carece absolutamente de valor en el establecimiento de la partida consignada en el respectivo libro". 
recurrir al diccionario de la Real Academia Española ${ }^{13}$, que lo define en su acepción pertinente como "Perteneciente o relativo a la casa u hogar", concepto que se opone claramente al carácter público del establecimiento de comercio, empresa, estudio u oficina que caracterizan al domicilio donde ejerce su actividad el contribuyente, motivo por el cual sería extraordinariamente raro que dichos documentos pudieran ser fiscalizados en la casa $\mathrm{u}$ hogar del contribuyente (donde normalmente se ubican), pues no estarían bajo la esfera pública que puede revisar el fiscalizador.

\section{La simulación ilícita o evasión.}

Es evidente que la simulación ilícita en materia tributaria -o evasiónsiempre será antijurídica, pues en ella se está fingiendo la celebración de un acto o contrato, con el preciso ánimo de provocar un perjuicio al fisco, mediante el pago de menos tributos.

Dichos actos o contratos obviamente son no fidedignos, pues se está ocultando mediante la mentira la realización de un hecho gravado, que ya se llevó a cabo, pudiendo incluso el Servicio prescindir del acto simulado, determinando el real monto de los impuestos que debería pagar en definitiva el contribuyente, cuando genera operaciones no fidedignas o falsas conforme al artículo 21 del Código Tributario.

Por otro lado, el fenómeno de la evasión dará lugar a las distintas figuras penales contenidas en particular en el artículo 97 del Código Tributario, cuando ésta se realice "maliciosamente", es decir, en virtud de un dolo directo de engańar y perjudicar al fisco.

Al contrario, cuando la evasión se lleva a cabo en virtud de un dolo normal, de aquél que se presume en el artículo $1^{\circ}$ del Código Penal, no constituirá delito tributario, aun cuando puede llegar a configurar una falta administrativa, como se expresará más adelante.

\section{La elusión y el fraude a la ley.}

a) Sobre el concepto de fraude a la ley y de abuso de un derecho. Hemos señalado que en general la elusión no es antijurídica ni ilícita. Sin embargo, ¿qué sucede cuando conjuntamente con un acto elusivo existe fraude a la ley o abuso de un derecho? ${ }^{14}$.

${ }^{13}$ Diccionario Real Academia Española, s. v., www.rae.es

${ }^{14}$ Para un cierto sector de la doctrina extranjera no se acepta la existencia de la institución del fraude a la ley. Véase Alcalde Rodríguez, Enrique, Teoría del fraude a la ley, en II Curso De Actualización Jurídica: "Teorías Del Derecho Civil Moderno (Santiago, Ediciones de la Universidad del Desarrollo, 2005), pp. 18-19: "Corresponde prevenir que cierto sector de la doctrina comparada se plantea en contra de la represión genérica del fraude a la ley, es decir, se pronuncia a favor de su eficacia salvo 
Para esbozar un concepto del fraude a la ley, seguiremos las opiniones de Alcalde ${ }^{15}$, quien expresa: "En lo tocante a nuestro medio jurídico, Fueyo entiende que hay fraude a la ley cuando por actos reales (no simulados) $\mathrm{y}$ voluntarios aunque a veces sin que exista necesariamente intención fraudulenta a juicio de la mayoría, se crea de hecho una situación aparentemente lícita y conforme a la ley, tomada ésta en su literalidad; pero que tiene como efecto violar el espíritu de la ley, pudiendo infringir a este respecto el contexto o bien normas determinadas./ Vial del Río, por su parte, señala que está constituido por "aquellos procedimientos en sí lícitos o en maniobras jurídicas a veces ingeniosas, que tienen la apariencia de legalidad y que, sin embargo, permiten realizar lo que la ley prohíbe o no hacer lo que la ley ordena./ Fraude a la Ley y Abuso del Derecho: Para cierto sector de la doctrina, ambas instituciones se hallan vinculadas en una relación de género a especie, distinguiéndose el fraude a la ley por el hecho de que la ilicitud no se manifiesta prima facie, a diferencia de lo que ocurre con las situaciones de abuso./ Por otra parte, si el abuso del derecho es concebido con el criterio finalista o social, las relaciones se

que la propia ley establezca expresamente una sanción para el evento que éste se configure en una determinada situación./ Se aduce, en abono de esta tesis, que además de los inconvenientes que provoca la consagración de la teoría del fraude respecto de la seguridad jurídica y la posibilidad de pavimentar el camino a la arbitrariedad judicial, su aceptación importaría, en muchas ocasiones, invertir los principios más propios y característicos del derecho privado. En efecto, según esta opinión, no cabe en este ámbito hablar de prohibiciones virtuales o tácitas, aunque se invoquen, para fundarlas, el orden público y las buenas costumbres. Los negocios que no han sido expresamente prohibidos, deben entenderse permitidos y, si existe prohibición, necesariamente ésta debe ser objeto de una interpretación restrictiva. Desde este punto de vista, expresa un autor que "no tendría ni sentido siquiera una prohibición que abarcara todo el ámbito de la acción posible por el hombre, porque al alcanzar tal extensión, reduciría todas las acciones a la misma clase, es decir, haría desaparecer la distinción entre acción prohibida y no prohibida, cuando precisamente lo que se quería al establecer la prohibición era distinguir como prohibidas ciertas acciones. Así como la música se oye sobre un fondo de silencio, sólo un fondo de libertad permite entender el sentido de las normas del derecho que la limitan o restringen./ No obstante, la opinión predominante se inclina por reprimir las figuras de fraude a la ley, con absoluta independencia de que las legislaciones de que se trata carezcan de un precepto legal concreto que lo sancione. Y así, por ejemplo, se ha destacado lo contradictorio que resultaría que la ley tolerara el fraude, pues sería pensar que prohíbe un resultado y que, a la vez, permite alcanzarlo (siempre bien entendido que lo prohibido sea el resultado, y no un determinado medio de conseguirlo); sería contradictorio, porque sería pensar que prohíbe la infracción a cara descubierta, y permite -ya que el fraude es también infracción- la solapada, que es aún más censurable, si cabe".

${ }^{15}$ Alcalde, cit. (n.15). 
hacen más estrechas, porque abusa del derecho subjetivo quien lo desvía del fin para el cual ha sido otorgado y actúa con fraude aquel que busca eludir una norma obligatoria utilizando para ello un camino concebido por el Derecho Positivo, aunque con un fin diverso. De este modo, se ha podido sostener que el fraude a la ley en el Derecho Internacional Privado, el abuso de poder en Derecho Administrativo y el abuso del derecho en el Derecho Privado son instituciones que expresan la misma idea. Desbois, en la misma línea, piensa que el abuso es un género de actos ilícitos y el fraude una especie de ese género, caracterizado por los rodeos empleados, por las combinaciones ingeniosas; en el abuso, en cambio, no se emplean tales expedientes, la violación es más directa. En igual sentido, Ruiz Luján plantea que "en todo abuso del derecho hay un fraude a la ley que lo establece y garantiza y en toda violación indirecta de la ley hay un abuso del derecho respectivo".

Fueyo ${ }^{16}$, por su parte, distingue ambos conceptos: "En cuanto a diferencias, siguiendo en parte a José Puig Brutau y a otros, se expresará lo siguiente:/ a) En el acto en ejercicio abusivo de los derechos concurre una sola norma, aquella de la cual emana el derecho subjetivo que se ejerce abusivamente, mientras en el fraude a la ley nos encontramos a lo menos ante dos, la ley defraudada y la de la cobertura, sin contar la posible pluralidad de normas en uno y otro caso". (b) Mientras en el acto en ejercicio abusivo de los derechos no puede faltar el daño a un tercero, por constituir un requisito de existencia, en el acto en fraude a la ley puede faltar dicho efecto, si bien es normal que se cause daño, y, finalmente./ c) Por sobre todo, en el acto en ejercicio abusivo de un derecho se está ejerciendo una atribución que el sujeto tiene reconocida, pero hay una extralimitación que produce un efecto dañoso a un tercero; en cambio en el fraude a la ley se busca un derecho a través de una norma que no merece ser aplicable y que, sin embargo, se intenta emplear fraudulentamente para dejar de aplicar otra que se ha resuelto eludir./ ch) Que tratándose del ejercicio abusivo de los derechos, en la generalidad de los casos la gravedad tiene cierto limite y es menor, y, en cambio, tratándose de fraude a la ley, las consecuencias, en cuanto a gravedad, serán generalmente mucho mayores y el área de afectación será más extendida. De ahi que la legitimación activa sea más amplia, que el efecto causado pueda alcanzar a una figura penal según la norma defraudada. No olvidemos, finalmente, que se ha intentado burlar, o se ha burlado, una norma prohibitiva o imperativa incluida por el orden público".

${ }^{16}$ Fueyo Laneri, Fernando, El fraude a la Ley, en Revista de Derecho y Jurisprudencia 88 (1991), disponible en "Base de datos" www.microjuris.com. 
Justamente, Fueyo ${ }^{17}$, en la obra antes citada, pone como ejemplo de fraude a la ley aquellas figuras llevadas a cabo precisamente para eludir impuestos al señalar: "Las leyes, muchas veces, contienen normas expresas que contrarrestan "a priori" los intentos maliciosos de aprovechar modalidades más beneficiosas o menos gravosas. Se persigue contrarrestar posibles fraudes a la ley que sería fácil de cometer a no mediar esas disposiciones de resguardo o prevención convenientemente estudiadas. Podrían citarse muchos ejemplos en la historia legislativa nacional; pero ninguno de tanta envergadura, con empleo de tanta agudeza sobre el eventual fraude, ni tan reciente, como el de la Ley $\mathrm{N}^{\circ} 18.985$, publicada en el Diario Oficial de 28 de junio de 1990, que se refiere a una importante reforma tributaria. Esta reforma está destinada, entre otras cosas, al ingreso de contribuyentes agricultores y transportistas al sistema de renta efectiva en reemplazo del de renta presunta, como sucedía hasta el momento. Se dispusieron expresamente normas cautelares del interés fiscal para impedir cualquier intento, hasta el más difícil de imaginar, a fin de que el contribuyente encontrara cerrado cualquier camino conducente al fraude a la ley. La prolija agudeza empleada por el legislador a este respecto contempló toda clase de actos o contratos destinados a un fin fraudulento. Se acudió a la asesoría técnica de abogados expertos en materia tributaria, justamente aquellos que aconsejan habitualmente al contribuyente deseoso de pagar el mínimo de impuestos".

En virtud de lo antes expuesto, por nuestra parte tenemos que señalar que en nuestra vida práctica parte importante de los actos elusivos habrán sido ejecutados en fraude a la ley o en abuso de un derecho, utilizando figuras expresamente reconocidas por el ordenamiento jurídico, pero persiguiendo finalidades no autorizadas por ésta, ya sea abusando de los derechos que éste les confiere a los contribuyentes, o haciéndolo en fraude a la ley.

b) Fuente legal de la institución del fraude a la ley. Que el fraude a la ley, pese a no estar consagrado expresamente en nuestra legislación, es un principio general del Derecho, lo ha expuesto en forma clarísima Domínguez ${ }^{18}$ al señalar: "Así entonces, a lo largo de todo el Código Civil volvemos a encontrar esa repugnancia al fraude: para impedir el provecho que su descubrimiento pudiere implicar, o para castigar con inhabilidad o con cesación en cargos si el titular ha actuado con fraude; para sancionar patrimonialmente al fraudulento, para obligarle a indemnizar los daños

${ }^{17}$ Fueyo, Fernando, cit. (n. 17).

${ }^{18}$ Domínguez Aguila, Ramón, "Fraus omnia corrumpit": Notas sobre el fraude en el Derecho Civil, en Revista de Derecho y Jurisprudencia 89 (1992) 3, "Base de datos" www.microjuris.com 
causados, aunque a él se le deba algo equivalente por parte del defraudado, para anular el acto fraudulento en perjuicio de terceros./ Si pues el fraude no se admite en todas esas y en otras hipótesis, ¿cómo admitir que fuera de ellas, el fraude no haya de recibir sanción? ¿Cómo entender que tales reglas sean sólo la consagración de sanciones específicas y sujetas, por lo mismo a un verdadero principio de especialidad, y no las demostraciones de un principio general, que las informa todas, principio que, por lo mismo, es posible extrapolar a todo caso de fraude? Porque ¿qué justificaría que pudiera sancionarse legislativamente al guardador fraudulento, por traicionar la confianza que en él se ha depositado, mas no al mandatario que con tanto o mayor confianza ha recibido el encargo de su mandante, o al promitente vendedor que burla su obligación? No es pues necesario ir más lejos para descubrir también en el Derecho Positivo la consagración del principio "fraus omnia corrumpit", porque no es por mero capricho o casualidad legislativa que el Código Civil sanciona en no menos de veinte disposiciones, maniobras fraudulentas en instituciones diversas y sin que entre ellas exista otro elemento común que el fraude".

Por otro lado, $\mathrm{Fueyo}^{19}$ ofrece soluciones positivas más concretas, al señalar: "Aunque el fraude a la ley no está consagrado en el artículo 10 del Código Civil, es incuestionable que, siendo, sin embargo, expresión incontestable de represión del "acto contra legem", este valioso género sirve precisamente para apoyar el argumento en orden a que en el artículo 10 debemos encontrar un germen lógico para la admisión legislativa del fraude a la ley, en nuestro propio Código, al menos indirectamente./ En el artículo 22 del Código Civil encontramos una nueva oportunidad de fundamentación en texto indirecto. Expresa dicha norma: "el contexto de la ley servirá para ilustrar el sentido de cada una de sus partes, de manera que haya entre todas ellas la debida correspondencia y armonía./ Los pasajes oscuros de una ley pueden ser ilustrados por medio de otras leyes, particularmente si versan sobre el mismo asunto./ Se reitera que la forma de dar con la norma defraudada es, justamente, a través del contexto de la legislación, o sea, el sistema, el todo. No a través de particularismos de normas determinadas, procedimiento que se aplicará sólo en ocasiones, podría decir raramente./ Aún más, cuando decimos sistema, o elemento sistemático, también estamos aludiendo al módulo "espíritu general de la legislación”, que es algo así como los principios generales de derecho si empleamos en esto algo de buena voluntad. Se trata del artículo 24 del Código Civil./ También puede agregarse el artículo $1467 \mathrm{del}$ Código Civil, el cual nos exige una causa 'real y lícita', y en la ley de la cobertura, la

${ }^{19}$ Fueyo, Fernando, cit. (n.17) 
empleada en el fraude, hay una causa ilícita ${ }^{20}$. Además, puede aducirse la presencia de objeto ilícito, por tratarse de un acto o contrato 'prohibido por las leyes', según lo dispone el artículo 1466 del Código Civil./ Finalmente, cabe fundarse en el principio general de la buena fe, que domina todo el derecho y también los actos y contratos. Quien obra en fraude de la ley no procede de buena fe, por el contrario, de mala fe".

c) ¿Es antijurídica la elusión efectuada en fraude a la ley o en abuso de un derecho? La Corte Suprema ha sostenido aparentemente que la elusión es una figura lícita, cualquiera que sea la intencionalidad del contribuyente al llevarla a cabo. Así lo ha señalado en la ya célebre sentencia dictada en causa rol No 4.038-0 $1^{21}$, que en su parte pertinente, expresa: " $\left.18^{\circ}\right)$ Que, así, el servicio confunde, en este caso, dos conceptos juridicos que tienen una diferencia notoria: el de evasión tributaria-ilícito-, con el de elusión, que consiste en evitar algo con astucia, lo que no tiene que ser necesariamente antijurídico, especialmente si la propia ley contempla y entrega las herramientas al contribuyente, como aqui ocurre, para pagar impuestos en una medida legitima a la que se optó, y no en aquella que se le liquida.I $\left.19^{\circ}\right)$ Que, en la presente situación, ello se ha hecho mediante la constitución de dos sociedades, aunque por las mismas personas, para explotar en conjunto un negocio, utilizando los beneficios tributarios que la propia ley entrega $y$, de este modo una, la requerida en el presente asunto, se hace cargo de la parte inmobiliaria, y la otra del aspecto mobiliario y de prestación de servicios, por todo lo cual se paga el impuesto que se pretende, en este segundo caso, como se indica en las ya tantas veces dichas liquidaciones. Ello no sólo es lícito, por tener un fundamento legal, sino que puede tener finalidades ajenas a la elusión de impuestos, como podrá serlo el facilitar la adquisición, administración y mantención de los muebles, operaciones que, como resulta lógico entender, son más frecuentes que la de los primeros, sujetos a menor desgaste".

${ }^{20}$ En dicho sentido, la Corte Suprema, en fallo de 7 de diciembre de 1998 ("Base de Datos" www.microjuris.com ), aunque no se pronuncia sobre el punto en su parte decisoria, hace suya esta postura en su considerando $12^{\circ}$, al señalar: "Que al respecto debe concluirse que un contrato de trabajo de plazo indefinido, está otorgando al trabajador la situación de estabilidad relativa con sus consiguientes eventuales derechos, el cual no puede ser modificado por las partes, transformándolo en otro, por obra o servicio determinado, ya que ello implicaría para el trabajador renunciar a su situación de estabilidad relativa que habia adquirido. Tal renuncia está prohibida por la ley y, en consecuencia, es nula de nulidad absoluta por ilicitud del objeto. No puede dejar de omitirse analizar la situación jurídica del empleador, en cuanto propuso y suscribió la cláusula, tras lo cual hay un fraude a la ley, una infracción a la normativa sobre estabilidad relativa que consulta nuestro Código Laboral, en lo cual media también un vicio de nulidad, por ilicitud de la causa".

${ }^{21}$ Ugalde - García, cit. (n. 10) 
La anterior sentencia pareciera consagrar el principio de la licitud plena de la elusión, por tener el actuar del contribuyente su base en el hecho de que "la propia ley contempla y entrega las herramientas al contribuyente, como aqui ocurre, para pagar impuestos en una medida legítima a la que se optó, y no en aquella que se le liquida”, lo que más adelante califica como un "fundamento legal".

Sin embargo, señala respecto de la elusión que "no tiene que ser necesariamente antijuridica" por lo cual implícitamente distingue entre elusión lícita e ilícita, calificando los hechos de la causa de la primera forma, aceptando implícitamente que puedan existir figuras de elusión ilícita, más aún cuando, justificando de alguna forma su resolución, indica que puede existir en los hechos materia del proceso "finalidades ajenas a la elusión de impuestos".

La verdad es que la sentencia en sí nos parece contradictoria, pues si en un principio acepta como elusivo, y por tanto legítimo, el actuar del contribuyente por atenerse a la ley, y luego acepta que exista elusión antijurídica, no entendemos cómo podría existir esta última si el contribuyente actúa dentro de la ley. Se está o no dentro de la ley, no puede haber figuras intermedias.

Sin perjuicio de lo dicho, tenemos que señalar que el artículo 97 No 4 inciso $2^{\circ}$ parte final del Código Tributario sanciona: "El empleo de otros procedimientos dolosos encaminados a o cultar o desfigurar elverdadero monto de las operaciones realizadas o a burlar el impuesto".

Claramente, la anterior es una figura penal residual, aplicable a todas aquellas conductas que no hayan sido tipificadas como delito tributario en las demás normas del Código Tributario o en las leyes especiales de índole tributaria.

De acuerdo al diccionario de la Real Academia Española "burlar" significa: "Engañar (inducir a tener por cierto lo que no lo es). Esquivar a quien va a impedir el paso o a detenerlo. Frustrar, desvanecer la esperanza, el deseo, etc., de alguien"22.

Como se percibe claramente, el tipo penal en cuestión sanciona dos situaciones distintas: el empleo de otros procedimientos dolosos tendientes a ocultar o desfigurar el verdadero monto de las operaciones (claramente la evasión dolosa), y el empleo de otros procedimientos dolosos encaminados a burlar el impuesto (elusión dolosa).

Por otro lado, no debemos perder de vista que el mencionado artículo 97 No 4 inciso $1^{\circ}$ no hace sino recoger con especialidad, y en forma mucho más agravada, lo que de alguna manera siempre ha estado sancionado en

${ }^{22}$ Diccionario Real Academia Española, s. v., www.rae.es 
el artículo 471 No 2 del Código Penal, que sanciona "al que otorgare en perjuicio de otro un contrato simulado", norma casi idéntica al artículo 466 inciso $2^{\circ}$ del mismo Código.

Por tanto, la disposición antes reseñada del artículo 97 № 4 del Código Tributario no es original ni exclusiva del ámbito tributario, sino que es una expresión particular de un principio más general de nuestro Derecho, en cuanto se tutela el patrimonio de terceros que pudieren verse perjudicados por simulaciones de contratos, libremente acordados, en virtud de la autonomía de la voluntad, según las reglas de todos conocidas del Código Civil.

El artículo 97 No 4 inciso $1^{\circ}$ del Código Tributario tiene su símil en el artículo 109 de la misma ley, que señala: "Toda infracción a las normas tributarias que no tenga señalada una sanción especifica, será sancionada con multa no inferior a un uno por ciento ni superior a un cien por ciento de una unidad tributaria anual, o hasta del triple del impuesto e l u d i do si la contravención tiene como consecuencia la e v a sió n del impuesto".

Nótese que el artículo 109 trascrito sanciona toda infracción a las leyes tributarias, fijando como parámetro los impuestos eludidos o evadidos, haciendo sinónimos ambos conceptos.

En virtud de ambas normas analizadas, tenemos que concluir que todo acto de evasión o elusión, ya sea ejecutado con dolo directo (en cuyo caso se aplicaría el artículo 97 № 4 inciso 1\%), o meramente voluntario o incluso culposo (en cuyo caso se aplicaría el artículo 109), constituyen actos antijurídicos para nuestra legislación tributaria, y por ende sancionables como delitos o como faltas, según sea el caso.

Por lo demás, tal ha sido el criterio esgrimido implícitamente por el Servicio de Impuestos Internos, al presentar sendas querellas por delitos tributarios por uso fraudulento de pérdidas tributarias en fusiones de empresas, antes de la entrada en vigencia de la Ley No 19.738 que restringió fuertemente su utilización.

Lo anterior ha sido arduamente debatido en el medio jurídico tributario, en que se ha señalado por sus detractores que las transacciones de empresas con pérdidas ocurridas con anterioridad a la entrada en vigencia de la Ley No 19.738, corresponden a operaciones ejecutadas al amparo de la normativa legal imperante hasta entonces, incluso cuando el único activo de la sociedad fuera la citada pérdida; y que aquellas utilizaciones de pérdidas incluso fuera del grupo empresarial, realizadas antes de la vigencia de la Ley No 19738 son perfectamente válidas, y no dan lugar a ningún ilícito tributario, ni mucho menos a un delito ${ }^{23}$.

\footnotetext{
${ }^{23}$ Silva, Mario en El Diario Financiero, de 20 de septiembre de 2004.
} 
Se podrá decir que las normas anteriores son claramente inconstitucionales por constituir leyes penales en blanco (así lo consideramos por lo demás, y así se ha sostenido), pero se trata de una ley vigente, que no ha sido derogada ni declarada su inaplicabilidad por parte del Tribunal Constitucional.

Sobre este punto, debemos sí hacer una distinción necesaria, en cuanto a que, a nuestro juicio, no todo acto elusivo constituiría delito, sino que sólo aquéllos respecto de los cuales se lograra probar efectivamente que tuvieron como único objetivo perjudicar al fisco, prueba de suyo muy difícil de producir por quien lo alega, dada la subjetividad involucrada en el acto o contrato.

Se ha sostenido en una forma un poco liviana en nuestro medio que, para que el contrato celebrado en fraude a la ley o en abuso de un derecho sea ilícito debe carecer de un "legítima razón de negocios que lo respalde", opinión que nos parece equivocada pues, lo que debería probarse en el juicio es que la intención de las partes era burlar el impuesto, lo que se podrá probar por todos los medios que establece la ley.

Ahora bien, si dicho contrato carece de alguna legítima razón de negocios, será un antecedente más para llegar a dicha convicción, pero sólo servirá de base más o menos fundada de una presunción judicial, mas no será el único antecedente de que podrá valerse el juez.

Determinar la voluntad de los contratantes será decisivo al momento de establecer si la elusión lo fue en fraude a la ley o no, generándose en definitiva un problema de interpretación sobre el concepto de " $\mathrm{b}$ u r $\mathrm{l}$ a $\mathrm{r}$ el i m p u e s t o ${ }^{24}$ que se exige al tipificar la figura delictiva residual ya

${ }^{24} \mathrm{El}$ tema no siempre ha sido pacífico, al respecto transcribimos lo señalado por Alcalde, cit. (n.15): "Elemento Intencional. A diferencia de los requisitos precedentes, donde en líneas generales existe cierta coincidencia en la doctrina, la discusión dista de ser pacífica al momento de averiguar si el fraude a la ley exige, por parte del agente, del elemento intencional constituido, según algunos, por el propósito de eludir o burlar la ley y, de acuerdo con otros, por el conocimiento que tiene el agente del obstáculo legal que se opone a la realización del interés perseguido./ Determinados autores, adhiriendo a un criterio objetivo, postulan que tal elemento no constituye un requisito del fraude a la ley, toda vez que mediante su sanción lo que se persigue no es reprimir la mala fe o intención maliciosa del agente, sino evitar que la ley no reciba aplicación; y no sería aplicada, lo mismo si el acto (fraudulento) se le sustrae de propósito, que sin él. En otras palabras, si el legislador se ha propuesto descartar determinados resultados perjudiciales, poco puede importarle que estos resultados hayan sido queridos, buscados por las partes, o que hayan sido indirectamente producidos por el ejercicio de buena fe de una actividad dirigida a un fin lícito. La sanción tendrá lugar igualmente, porque el designio del legislador es, principalmente, la exclusión de un resultado y no la represión de la intención de infringir la ley./ Conforme con esta posición, entonces, el acto será válido cuando la ley haya sido 
mencionada, que corresponderá al juez dilucidar, como bien lo ha señalado Fueyo ${ }^{25}$, al decir: "Tomando el camino de una decisión, si frente a la norma elegida aparece otra tratada de eludir, deberá aplicarse esta última. A la ficción creada artificialmente, con un deliberado propósito fraudulento y con aprovechamiento de sus consecuencias, se tendrá que responder corriendo el velo y alumbrando la verdad, la legalidad, la defensa del orden público y otros conceptos o valores indeterminados, la licitud, la conducta con arreglo a la corrección, la moralidad. De lo expuesto se desprende que la consecuencia que se produce no queda circunscrita a la ineficacia o nulidad del acto o contrato a través del cual se pretendió lograr un resultado fraudulento y provechoso, sino que ha de comprender, también, la efectiva aplicación de la norma debida que se encuentra comprendida, mediante la búsqueda e interpretación inteligentes, en el conjunto o sistema del ordenamiento; reitero, aunque no queden excluidas ciertas consecuencias anulatorias./ En resumen:/ a) El acto o contrato que aparece celebrado conforme a una normativa impropia por elección con fraude, dejará de estar regida por aquélla"./ b) Se estimará que el acto subsiste, como sano, pero regido por otra normativa, la debida. Alternativamente, se declarará ineficaz o nulo dicho acto o contrato fraudulento en el evento de no poder subsistir como válido por aplicación de las reglas generales./ "c) En cualquier caso se aplicará la norma debida, previa interpretación de todas las normas susceptibles de aplicación, lo que se hará conforme a un método de integración de lagunas, de adecuación de la norma al ambiente y la época, y descartando en general todo aferramiento a la literalidad de las normas, conducente a errores y perniciosos efectos. Si algo está contraindicado en

respetada aunque en concreto se acredite que las partes se propusieron infringirla y, será ineficaz, si objetivamente atenta contra la ley, aunque sus autores hayan creído, erróneamente, adecuarse a ella./ Siguiendo un criterio subjetivo, existe otro sector de la doctrina que exige, para efectos de entender configurado el fraude, la concurrencia del elemento intencional o finalidad de burlar la ley, obteniendo merced de ello el resultado que ésta procura evitar. Prescindir de este elemento, se dice, conduciría al absurdo lógico de pensar que pueden existir "fraudes sin fraude". De este modo, no se comprendería que se pudiese declarar nulo el divorcio de cónyuges pertenecientes primitivamente a un país en que el matrimonio sea declarado indisoluble y que, mucho tiempo después de haber adquirido la nacionalidad de un país diferente con una finalidad legítima, se hubieran divorciado conforme a las leyes de este país./ Adoptando una posición intermedia, pero sin duda interesante, algunos tratadistas estiman que aun cuando no constituiría un requisito del fraude la constancia de un obrar malicioso o intención manifiesta de burlar la ley, siempre será necesario un asiento de culpabilidad ya sea por la presencia de dolo directo, dolo eventual, culpa con previsión e incluso simple culpa".

${ }^{25}$ Fueyo, Fernando, cit. (n. 17). 
el tratamiento del fraude a la ley es precisamente la aplicación ciega de la ya fenecida escuela francesa de la exégesis".

Más adelante, y profundizando el tema de la integración e interpretación de la ley señala: "Para dar ejemplos concretos de normas en blanco que requieren un aporte necesario del juez para su aplicación al caso, podemos recurrir a nuestros códigos substantivos o adjetivos, no importa que se hayan promulgado hace 100 años o más./ Recordemos algunos casos. Cuando la ley maneja y decide por aplicación genérica los conceptos y vocablos de orden público, buenas costumbres, moral, interés público, buena fe, diligencia o cuidado, culpa, buen padre de familia, fuerza o violencia, justo o justa, depravación del padre o de la madre, inhabilidad física o moral, conocimiento de causa, apreciación de la prueba en conciencia, fallar en conciencia, prudencia, discrecionalidad, equidad, presunciones, indicios y circunstancias, sana crítica, convicción necesaria del juez del crimen para proceder a condenar, apreciación comparativa de los medios de prueba, etc., etc"./ Me pregunto: ¿Cómo se interpreta en estos casos? Pues mediante consideración de los hechos y circunstancias, debidamente probados, con el agregado de un razonamiento creador del juez que es, reitero una vez más, absolutamente necesario. Pero, es obvio, la solución no estaba exclusivamente en la ley: algo en la ley y el resto en el aporte personal del juez, para cuyo efecto éste deberá crear, mucho o poco, pero crear./ Pasando a la hipótesis general de integración necesaria por la vía de investigación creadora, debemos atender a lo siguiente./ Puede afirmarse que la ley no contiene todo el derecho que, en cada instante, necesita la sociedad para su vida normal. Por ello, quien tiene a su cargo la misión de interpretar y aplicar la ley realiza en muchos casos una función creadora./ La ley es el mínimo de Derecho posible generalizable, el máximo susceptible de positivización. Pero paralelamente, queda otro máximo de posibilidades nacientes de realidades normativas extrapositivas, de reglas no nacidas o de preceptos vivos no escriturados, de aspiraciones y deseos de justicia, en fin, de todo el resto del derecho que ha de tener cumplida realización en la función judicial. Precisamente por ser el juez, por propia naturaleza y función, justo. Este alguien que ejerce función creadora entendida del modo insinuado, trata, con todo, de encubrir tímidamente su labor con la palabra interpretación".

En virtud de lo expresado, el problema se traduciría en establecer si un contrato fue celebrado con la única finalidad de perjudicar al fisco, por lo cual de él se desprendería claramente su carácter doloso, aspecto este último que siempre deberá ser probado por parte de la autoridad, dada la exigencia de dolo directo de la figura delictiva.

Así las cosas, nos guste o no, la elusión dolosa efectuada con el único 
fin de burlar el impuesto constituye delito de acuerdo con la norma expuesta.

d) ¿Qué sucede con los impuestos eludidos dolosamente, en fraude a la ley o en abuso de un derecho? En estos casos claramente no estamos frente a operaciones no fidedignas o falsas, que consten en declaraciones, documentos, libros o antecedentes que tengan el carácter de no fidedignos, de aquellas respecto de las cuales el artículo 21 del Código Tributario permite prescindir, para el cobro del impuesto evadido, toda vez que en el acto ejecutado en fraude a la ley tributaria o en abuso de un derecho no se ha ocultado la existencia de un hecho gravado a la autoridad tributaria.

En efecto, el acto o contrato ejecutado en fraude a la ley o en abuso de un derecho es absolutamente fidedigno y verdadero, en él nada se ha ocultado a la Autoridad, de manera que no podemos predicar a su respecto que sea de aquellos actos no fidedignos, respecto de los cuales el Servicio pueda prescindir por vía administrativa, sin perjuicio del derecho de reclamación que siempre le asistirá al contribuyente para alzarse en contra de dicha calificación.

Pensamos que debe aplicarse el artículo 2314 del Código Civilen cuanto a que, acreditada la existencia del delito antes reseñado, debe ser tributariamente ilícito dicho actuar, por ser éste antijurídico, como todo delito.

Ha señalado Fueyo al respecto ${ }^{26}$ : "La ilicitud aparece como evidente porque es algo contrario o en oposición al derecho, o bien se cae en el exceso por ejercicio abusivo del derecho. En el evento de producirse daño, la ilicitud da lugar a su reparación./ La ilicitud puede conjugarse o coincidir con la antijuridicidad, que en este caso es específicamente civil desde el momento que la transgresión es a una norma civil. Esa antijuridicidad importa un juicio de menosprecio hacia el ordenamiento por parte de una determinada conducta transgresora./ Como primera aproximación podría afirmarse, pues, que el fraude a la ley arranca del acto jurídico denominado específicamente contrario a derecho, o antijurídico o ilícito./ [...] el fraude a la ley es la especie del género "acto contrario a la ley. [...]. Todo nace de la libertad que reconoce y concede el Derecho al hombre. Lo quiere libre en los términos más amplios y con los fines que sean, aunque luego deba intervenir por ser necesario".

No puede ser otra la solución, pues sería absolutamente incongruente con el espíritu general de nuestra legislación que un contribuyente pudiere ser sancionado penalmente por un acto ejecutado dolosamente, en fraude a la ley o abuso de un derecho, y, por el otro, que subsistiere el ahorro

\footnotetext{
${ }^{26}$ Fueyo, Fernando, cit. (n. 17).
} 
impositivo generado por dicho ilícito.

Algo similar sostiene Domínguez ${ }^{27}$, en cuanto a considerar la inoponibilidad del acto o contrato celebrado en fraude a la ley, generando la correspondiente indemnización de perjuicios, y, llevándolo nosotros al ámbito tributario, el cobro de los impuestos eludidos al emitir el acto inoponible al Fisco. Ha sostenido dicho autor: "En suma, pensamos que no es menester buscar justificación especial a la inoponibilidad del fraude. Ello se explica por la existencia del fraude mismo. Si hemos sostenido la vigencia del principio general traducido en el adagio "fraus omnia corrumpit" no creemos que sea necesario buscar una fundamentación a su sanción más allá del propio principio. Por algo es un principio general y su sanción se impone por la exclusión que ha de hacerse del fraude: Medio destinado a apartar la regla obligatoria, su sanción ha de ser aquella que restituya el imperio de ésta. No tiene pues sentido buscar otra fundamentación. Como dice un autor. "El acto fraudulento es sancionado en razón del vicio que lo infecta, el fraude, y no simplemente porque causa un perjuicio a otro. La solución dada al problema del fraude suprime lo más corrientemente por lo demás, la cuestión de responsabilidad, o más exactamente impide que se plantee".

Por su lado, así también lo expone Fueyo ${ }^{28}$ : "En cuanto a efectos "in concreto", puede afirmarse el siguiente principio general. Los efectos propios de la declaración de un acto en fraude a la ley, no implican necesariamente la nulidad automática de dicho acto fraudulento, sino la aplicación del efecto o sanción correspondientes a la violación de la ley defraudada y que se ocultó, al deshacerse la apariencia de protección de la ley de cobertura empleada para cometer el fraude. El acto en fraude no es nulo o no lo es directamente, sino que queda sometido a la sanción de la norma eludida, como si el fraude no hubiese existido".

e) ¿Bajo qué método debería declararse la inoponibilidad del acto fraudulento o en abuso de un derecho por parte del juez? Pensamos que en materia tributaria el fraude a la ley (y la simulación por cierto) siempre se va a manifestar en un acto jurídico, el que por regla general constituirá un contrato.

Ahora bien, el artículo 1560 del Código Civil señala que "Conocida claramente la intención de los contratantes, debe estarse a ella más que a lo literal de las palabras". De más está decir que se ha señalado por la doctrina que la referida norma es aplicable también a los actos unilaterales de voluntad ${ }^{29}$.

\footnotetext{
${ }^{27}$ Domínguez, Ramón, cit. (n. 19).

${ }^{28}$ Fueyo, Fernando, cit. ( n. 17).

${ }^{29}$ López Santa María, Jorge, cit. (n..5 ), p. 31.
} 
El problema a dilucidar es si en un contrato simulado, o celebrado en fraude a la ley o en abuso de un derecho, en que el juez llega a la convicción, mediante los diversos medios de prueba, que existió una voluntad distinta a la aparentemente manifestada, puede hacer prevalecer la primera en desmedro de la segunda, declarando así la inoponibilidad del contrato aparente y la supremacía de la voluntad oculta.

En este punto nos remitimos a las palabras de López Santa María ${ }^{30}$ que señala: "El intérprete debe acometer una verdadera investigación psicológica pues su propósito es lograr poner en claro la intención de los contratantes. Debe él hacer todo lo posible para llegar hasta la conciencia de los individuos. "La doctrina de la voluntad reduce la interpretación a la simple determinación de la intención de las partes, lo que es una mera cuestión de hecho, donde el trabajo del intérprete no es el de un jurista que aplica una regla, sino el de un psicólogo que percibe la intención de los contratantes, lo que es una operación de carácter puramente inductivo, tendiente, solamente, a la obtención de un conocimiento preciso de la verdadera intención./ [...] El artículo 1560 más que una regla de interpretación, sirve de principio rector a las reglas que le siguen en el Código. Su papel es superior al de una regla de interpretación, pues consagra en Chile, por sí solo, el sistema subjetivo tradicional de interpretación de los contratos, cuyo rasgo fundamental consiste en la búsqueda psicológica de la voluntad interna de las partes. De este modo, en cada ocasión en que los tribunales pronuncian un fallo interpretativo, ellos se refieren a dicha norma/. La interpretación de los contratos cuyo texto es claro y preciso: Respecto a Francia, hemos ya examinado latamente la cuestión concerniente a la posibilidad de interpretar un contrato cuyo texto es claro y preciso. Nuestra opinión se inclinó en el sentido de permitir la interpretación de cualquier contrato, pues la oscuridad de la declaración no es una condición para que proceda la interpretación. Importa ahora examinar, al menos sumariamente, cómo se presenta este problema en el Derecho chileno./ En Chile, al igual que doquiera que la discusión ha surgido, las opiniones son contradictorias tanto en la doctrina como en la jurisprudencia. Sin hacer un inventario de lo mucho escrito sobre este punto, cúmplenos destacar lo más representativo./ Risopatrón, en su diccionario de legislación y jurisprudencia chilenas, dice: "Interpretar es la determinación del sentido que debe darse a una frase o sentencia que parece obscura./ En el mismo sentido se pronuncia el diccionario de Escriche: 'Interpretar un contrato significa explicar o declarar el sentido del contrato que aparece oscuro o dudoso'. O sea que, al contrario, el con-

\footnotetext{
${ }^{30}$ López Santa María, Jorge, cit. (n.5), pp. 83, 85, 86 y 87.
} 
trato cuyo texto es claro no podría ser interpretado; sólo cabría aplicarlo tal cual aparece externamente. Es lo que piensa también Rojas Blanco: 'Es incuestionable que la interpretación sólo puede tener lugar cuando el sentido de una cláusula o del contrato en general adolecen de oscuridad o imprecisión'. Algunos fallos de la Corte Suprema han consagrado esta doctrina: 'La interpretación del contrato tiende a determinar la explicación o el sentido que debe atribuirse a las declaraciones o términos empleados en alguna convención, susceptibles de ambigüedad o de falta de precisión [...]'./ Cuando el contrato está concebido en términos claros y precisos, son inaplicables las reglas de interpretación del título XIII del libro IV del Código Civil que tienden a resolver las dudas que pueden nacer de pasajes obscuros o de inteligencia ambigua./ En el extremo opuesto se encuentra la doctrina que considera que todo contrato, claro u oscuro, puede ser interpretado. Después de haber sido sostenida por don Luis Claro Solar, uno de los más eminentes jurisconsultos chilenos, ella se ha impuesto en la actualidad, tanto en la teoría como en el foro. 'No hay que recurrir a la doctrina que distingue entre las cláusulas claras y las cláusulas obscuras de los contratos. Claras u obscuras, tendrán siempre que ser interpretadas o apreciadas en su verdadero sentido para fijar la intención y espíritu de las partes, ya que las cláusulas que para unas personas son suficientemente claras, pueden ofrecer dudas a otras'. En igual sentido, observa Brain Rioja: 'La primera actitud del intérprete no consiste en determinar si los términos son claros u obscuros para deducir la necesidad o no de interpretar; a la inversa, él debe proceder inmediatamente a la búsqueda de la intención de los contratantes'. Igualmente la Corte Suprema, al estatuir, en fallo de 8 de agosto de 1956: 'Según el artículo 1560 del Código Civil, que establece la regla fundamental sobre la interpretación de los contratos, el contrato es lo que expresa la declaración salvo si se llega a comprobar que los contratantes querían estipular una cosa determinada diferente./ Obra en favor de esta última doctrina la existencia del artículo 19 inciso $1^{\circ} \mathrm{del}$ Código Civil, el que, iniciando el parágrafo relativo a la interpretación de las leyes, prescribe: Cuando el sentido de la ley es claro, no se desatenderá su tenor literal, a pretexto de consultar su espíritu'. Si los redactores del Código Civil, después de haber prohibido la interpretación no literal de las leyes claras no reprodujeron esta norma en el parágrafo, dedicado a la interpretación de las convenciones, es precisamente porque a los contratos claros no se les aplica el mismo criterio que a las leyes claras./ Respecto a los contratos, sólo la comprobación de una voluntad clara permitiría prescindir de la interpretación. Pero, cuidado, bajo términos aparentemente claros y precisos puede ocultarse una voluntad diversa, por lo que no debe impedirse, a priori, el desenvolvimiento de la interpretación. Es 
lo que ha subrayado con acierto la Corte de Apelaciones de Santiago: 'En la interpretación de los contratos, a la inversa de lo que ocurre en la interpretación de la ley, la norma fundamental que el legislador seńala al intérprete consiste en buscar, antes que nada, la intención de los contratantes, aun por encima del tenor literal de las palabras"'.

f) Problema del procedimiento por seguir. Sin embargo, y ahora trasladando el tema al Derecho Tributario positivo chileno, pensamos que en materia tributaria debería existir sentencia ejecutoriada previa, dictada por el juez ordinario, que declare la existencia del fraude a la ley, por cuanto nos encontramos en una situación en que no existe simulación ilícita, en cuyo caso el artículo 21 del Código Tributario permite actuar al Servicio, aún sin sentencia previa que declare dicha simulación.

En efecto, cada vez que el legislador tributario ha detectado la existencia del fraude a la ley, ha procedido a evitar dichas formas de elusión, dictando la ley correspondiente, ordenando prescindir del contrato fraudulento, como si no hubiere existido, por lo menos desde el punto de vista tributario.

Así, por ejemplo, el Código, en su artículo 64, permite tasar el precio de venta de los bienes muebles e inmuebles a un valor comercial, cuando el señalado en el contrato sea notoriamente inferior al corriente en plaza, prescindiendo desde el punto de vista impositivo del fijado por las partes.

Otro caso es el artículo 21 de la Ley de Impuesto a la Renta, en que, por ejemplo, si una sociedad de personas otorga un préstamo a uno de sus socios persona natural, tal actuación se considera retiro, corrigiendo desde el punto de vista tributario dicha operación, sin afectar por supuesto dicho contrato desde un punto de vista civil.

A falta de norma general tributaria expresa, que permita prescindir del acto celebrado en fraude a la ley o en abuso de un derecho, pese a ser ilícito y antijurídico el actuar del contribuyente, pensamos que la única forma de declararlo sería mediante la correspondiente demanda de indemnización de perjuicios interpuesta en el respectivo juicio criminal ordinario ${ }^{31}$, pues el Código Tributario no establece un procedimiento especial para tal efecto. En dicha demanda el fisco debería valorar el monto de los perjuicios causados por el contribuyente mediante su actuar doloso, y proceder a solicitar que se le indemnicen los daños, no como determinación de impuestos adeudados, lo que sólo podría hacerse mediante liquidación de impuestos previa, en los términos del artículo 21 del Código Tributario,

${ }^{31}$ Materia que incluso podría dar lugar a una demanda civil de indemnización de perjuicios, tramitada conforme a las reglas generales del juicio ordinario ante el juez civil que corresponda. 
sino que como perjuicios causados por el hecho ilícito, conforme a las reglas generales del Código Civil.

[Recibido el 27 de septiembre y aceptado el 19 de octubre de 2007].

\section{BIBLIOGRAFÍA}

Alcalde Rodríguez, Enrique, Teoría del fraude a la ley, en II Curso De Actualización Juridica "Teorias Del Derecho Civil Moderno (Santiago, Ediciones Universidad del Desarrollo, 2005).

Brzovic González, Franco, La interpretación de las leyes tributarias, en VV.AA., Interpretación, integración y razonamientos jurídicos (Santiago, Editorial Jurídica de Chile, 1992).

Сомтоsto Canales Arnolfo, Manual de contabilidad para abogados (Santiago, Editorial Jurídica de Chile, 1996).

Diez DuARTE, Raúl, La simulación de contrato en el Código Civil chileno (2a Edición, Santiago, Fallos del Mes, 1982).

Domínguez Aguila, Ramón, "Fraus omnia corrumpit": notas sobre el fraude en el Derecho civil, en Revista de Derecho y Jurisprudencia 89 (1992) 3, "Base de datos" www.microjuris.com

Fueyo Laneri, Fernando, El fraude a la ley, en Revista de Derecho y Jurisprudencia 88 (1991), en "Base de datos" www.microjuris.com

López Santa María, Jorge, Sistemas de interpretación de los contratos (Valparaíso, Ediciones Universitarias de Valparaíso, 1971).

Pascal garcía-huidobro, Enrique, De las presunciones (Memoria de Prueba, Universidad de Chile, s.l., s.d.).

Rioseco EnríQuez, Emilio, La prueba ante la jurisprudencia (2a Edición, Santiago, Editorial Jurídica de Chile, 1995), II,

SomarRIVA UndurRaga, Manuel, Las obligaciones y los contratos ante la jurisprudencia, (Santiago, Editorial Nascimento, 1939).

Ugalde Prieto, Rodrigo - García Escobar Jaime, Elusión, planificación y evasión tributaria (Santiago, LexisNexis, 2006).

Diccionario Real Academia Española, www.rae.es

SiLVA, Mario en El Diario Financiero, de 20 de septiembre de 2.004. 

